Supplement of Solid Earth, 7, 549-556, 2016

http://www.solid-earth.net/7/549/2016/

doi:10.5194/se-7-549-2016-supplement

(C) Author(s) 2016. CC Attribution 3.0 License.

(c) (i)

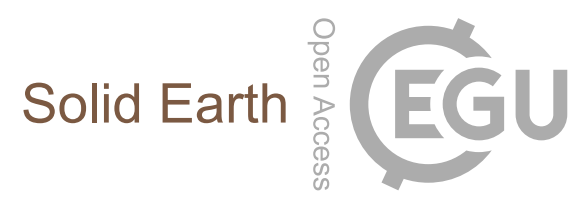

Supplement of

\title{
Effect of soil coarseness on soil base cations and available micronutrients in a semi-arid sandy grassland
}

\section{Linyou Lü et al.}

Correspondence to: Ruzhen Wang (ruzhenwang@iae.ac.cn)

The copyright of individual parts of the supplement might differ from the CC-BY 3.0 licence. 
Fig. S1 Proportion of soil clay particles for $0-10 \mathrm{~cm}$ soil in different soil coarseness degrees of $0 \%$ sand addition $(\mathrm{C} 0), 10 \%(\mathrm{C} 10), 30 \%(\mathrm{C} 30), 50 \%(\mathrm{C} 50)$ and $70 \%(\mathrm{C} 70)$. Data represent mean $\pm \operatorname{SE}(n=6)$. Letters indicate significant differences among treatments.

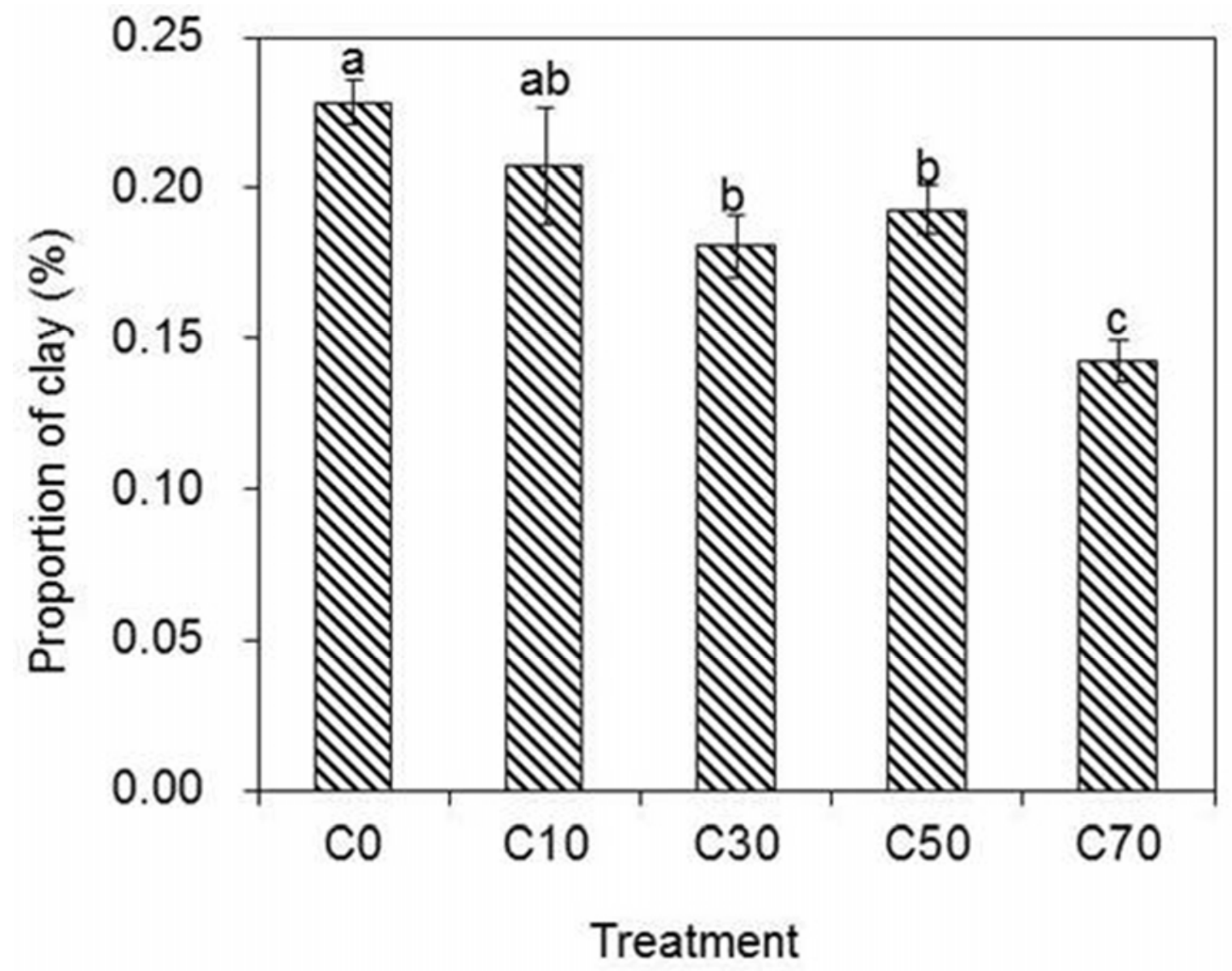

